\title{
Publisher Correction: Comprehensive analysis of chromothripsis in 2,658 human cancers using whole-genome sequencing
}

Isidro Cortés-Ciriano (iD, Jake June-Koo Lee (iD, Ruibin Xi(D), Dhawal Jain, Youngsook L. Jung, Lixing Yang, Dmitry Gordenin (D), Leszek J. Klimczak D, Cheng-Zhong Zhang (D), David S. Pellman, PCAWG Structural Variation Working Group, Peter J. Park (D) and PCAWG Consortium

Correction to: Nature Genetics https://doi.org/10.1038/s41588-019-0576-7, published online 5 February 2020.

In the version of this article initially published, author Peter J. Park had affiliation numbers 2 and 3; the correct affiliation numbers are 1 and 2. The error has been corrected in the HTML and PDF versions of the article.

Published online: 13 May 2020

https://doi.org/10.1038/s41588-020-0634-1

( ) The Author(s), under exclusive licence to Springer Nature America, Inc. 2020 